EGU21-10393

https://doi.org/10.5194/egusphere-egu21-10393

EGU General Assembly 2021

(c) Author(s) 2021. This work is distributed under

the Creative Commons Attribution 4.0 License.

\title{
Large-scale circulation changes over South America are impacting synoptic-scale tropical-extratropical interactions and altering rainfall seasonality
}

Marcia Zilli and Neil Hart

University of Oxford, School of Geography and the Environment, Oxford, United Kingdom of Great Britain - England, Scotland, Wales (marcia.zilli@ouce.ox.ac.uk)

During austral summer, persistent tropical-extratropical (TE) cloud bands, such as the South Atlantic Convergence Zone (SACZ) over South America, link tropical humid areas to the subtropics. Changes in circulation due to global warming is already impacting the location and duration of these TE cloud bands, affecting the hydrological regime of the subtropics. In this study, we present an automatic object-based identification of TE cloud bands which we utilize to obtain an event set of TE cloud bands over South America. This approach and our newly-identified sample base are ideal for understanding interactions between the variability and change in the regional mean state and synoptic-scale weather systems. TE cloud bands are responsible for almost $60 \%$ of the subtropical precipitation during the South America rainy season (November to March), mostly produced by SACZ events, a TE cloud band persisting for four or more days. Their location and persistence are modulated by the propagation of synoptic-scale extratropical disturbances interacting with intraseasonal variability in the basic state upper-level zonal wind. The persistent SACZ events (i.e., lasting four or more days) are supported by upper-level westerly anomalies over the subtropics caused by an anomalous trough in the subtropical jet which favours the propagation extratropical disturbances deeper into the tropics. Conversely, transient events occur when the Bolivian High is displaced/expanded southeastward, resulting in upper-level easterly winds occurring over subtropical latitudes and blocking the equatorward propagation of Rossby waves.

In recent decades, changes in circulation due to global warming has affected the basic-state circulation, resulting in different impacts in transient and persistent TE events throughout the rainy season. Over South America, the number of days with TE events has decreased during the rainy season peak but increased during onset and cessation months, resulting in the displacement of accumulated precipitation into early and late summer. These results are obtained by comparing two periods: 1979-1996 and 1997-2018, excluding ENSO years. These synoptic-scale changes are related to changes in the position of the subtropical jet and its trough, impacting on the propagation of RW towards South America. In the beginning (November) and end (February) of the rainy season, the westerlies have become stronger over subtropical South America, favouring the development of more persistent events and resulting in an increase in the total precipitation during TE events. During the peak of the rainy season (December and January), changes in upper- 
level circulation have reduced the conditions necessary to the development of TE events, affecting the total precipitation during these months. We show that anomalous subtropical convection from the cloud bands is a source of Rossby waves that interact with the basic flow, resulting in downwind enhancement or damping of the extratropical disturbances. Therefore, these contemporary changes over South America are likely to have implications for changes Rossby Wave spectra in the Southern Hemisphere, especially downstream from the SACZ. 